\title{
The Effect of Charge at the Surface of Silver Nanoparticles on Antimicrobial Activity against Gram-Positive and Gram-Negative Bacteria: A Preliminary Study
}

\author{
Abbas Abbaszadegan, ${ }^{1}$ Yasamin Ghahramani, ${ }^{1}$ \\ Ahmad Gholami, ${ }^{2}$ Bahram Hemmateenejad, ${ }^{3}$ Samira Dorostkar, ${ }^{3}$ \\ Mohammadreza Nabavizadeh, ${ }^{1}$ and Hashem Sharghi ${ }^{3}$ \\ ${ }^{1}$ Department of Endodontics, Faculty of Dentistry, Shiraz University of Medical Sciences, Shiraz, Iran \\ ${ }^{2}$ Department of Pharmaceutical Biotechnology and Pharmaceutical Sciences Research Center, School of Pharmacy, \\ Shiraz University of Medical Sciences, P.O. Box 71345-1583, Shiraz, Fars, Iran \\ ${ }^{3}$ Chemistry Department, Shiraz University, Shiraz, Iran \\ Correspondence should be addressed to Ahmad Gholami; gholami@sums.ac.ir
}

Received 15 June 2014; Revised 17 September 2014; Accepted 18 September 2014

Academic Editor: Ronen Hazan

Copyright (C) 2015 Abbas Abbaszadegan et al. This is an open access article distributed under the Creative Commons Attribution License, which permits unrestricted use, distribution, and reproduction in any medium, provided the original work is properly cited.

\begin{abstract}
The bactericidal efficiency of various positively and negatively charged silver nanoparticles has been extensively evaluated in literature, but there is no report on efficacy of neutrally charged silver nanoparticles. The goal of this study is to evaluate the role of electrical charge at the surface of silver nanoparticles on antibacterial activity against a panel of microorganisms. Three different silver nanoparticles were synthesized by different methods, providing three different electrical surface charges (positive, neutral, and negative). The antibacterial activity of these nanoparticles was tested against gram-positive (i.e., Staphylococcus aureus, Streptococcus mutans, and Streptococcus pyogenes) and gram-negative (i.e., Escherichia coli and Proteus vulgaris) bacteria. Well diffusion and micro-dilution tests were used to evaluate the bactericidal activity of the nanoparticles. According to the obtained results, the positively-charged silver nanoparticles showed the highest bactericidal activity against all microorganisms tested. The negatively charged silver nanoparticles had the least and the neutral nanoparticles had intermediate antibacterial activity. The most resistant bacteria were Proteus vulgaris. We found that the surface charge of the silver nanoparticles was a significant factor affecting bactericidal activity on these surfaces. Although the positively charged nanoparticles showed the highest level of effectiveness against the organisms tested, the neutrally charged particles were also potent against most bacterial species.
\end{abstract}

\section{Introduction}

Nanoparticles are known as particles with a size smaller than $100 \mathrm{~nm}$ [1]. By reducing the particle size from the micrometre to the nanometre scale, almost all the physical, chemical, and biological characteristics of the materials (e.g., hardness, active surface area, and antibacterial activity) will be altered [2]. Accordingly, it has been proven that inorganic nanoparticles with special characteristics display antibacterial activity [3]. Likewise, some of the metal nanoparticles have shown to have favourable bactericidal effects against gram-positive and gram-negative bacteria, among which silver nanoparticles
(AgNPs) are well known for this criterion [4]. Although, due to wide target of AgNPs attack, the mechanisms involved in antibacterial activity of AgNPs are not completely clear, the microorganisms do not seem to become resistant against silver [2].

The bactericidal effect of AgNPs depends on different parameters including size, shape, and the surface charge of the particles. In this respect, smaller particles are found to have greater antibacterial activity and shown to have two benefits. Firstly, they can easily reach the nuclear content of bacteria due to the structure of the bacterial cell wall, especially in gram-negative ones [5]. Secondly, they can provide a greater 
surface area and therefore stronger bactericidal interactions $[2,6]$. Some studies revealed that the NPs greater than $10 \mathrm{~nm}$ accumulate on the cellular surface and compromise cellular permeability; however, NPs smaller than $10 \mathrm{~nm}$ penetrate into the bacteria, affecting DNA and the enzymes leading to cellular death $[7,8]$.

As stated, the antibacterial activity of AgNPs also depends on the morphology of the particles. Pal et al. [2] demonstrated that AgNPs with the same surface areas but with different shapes can exhibit dissimilar microbicidal activity. This effect might be related to the difference in their effective surface areas and number of active facets. Furthermore, the electrostatic attraction between positively charged nanoparticles and negatively charged bacterial cells is shown to be another important aspect with regard to the antimicrobial activity of the AgNPs [3,9]. Although gram-positive and gram-negative bacteria have differences in their membrane structure, most of them have a negative charge. The gramnegative bacteria have a layer of lipopolysaccharide at the external surface followed by a thin layer of peptidoglycan [10]. On the other hand, the cell wall in gram-positive bacteria is mainly composed of a thick layer of peptidoglycan [11]. It has been shown that the AgNPs were more active against gramnegative bacteria, regardless of their resistance level $[12,13]$.

Depending on the method of synthesis, AgNPs can exhibit a broad size and shape distribution, different surface charges and varying levels of bioactivity. In this respect, the capping agents and stabilizers, which are normally used to change the surface charges of the nanoparticles, can also influence the bioactivity of the AgNPs [14-17]. In a previous study the superiority of the positively charged AgNPs over the negatively charged particles, in terms of the antibacterial activity, was demonstrated [18] but there is no report evaluating the bioactivity of the neutral AgNPs. In the current study, different capping agents were employed to fabricate AgNPs with positive, negative, and neutral surface charges, and the role of surface charge in their bacterial activity was assessed. The neutrally and negatively charged particles were synthesized according to a previously known methodology $[19,20]$ while the positively charged particles were synthesized for the first time.

The goal of this study is to investigate the influence of different surface charges of AgNPs (positive, neutral, and negative) on their antibacterial effectiveness against a panel of human pathogens, associated with water, air, and food including gram-positive (i.e., Staphylococcus aureus, Streptococcus mutans, and Streptococcus pyogenes) and gramnegative (i.e., Escherichia coli and Proteus vulgaris) bacteria.

\section{Materials and Methods}

2.1. Synthesis and Characterization of the AgNPs. Three groups of AgNPs with different surface charges were synthesized as follows.

(i) Negatively Charged AgNPs. These AgNPs were synthesized through the reduction of silver nitrate using sodium borohydride, according to the method proposed by Mulfinger et al. [19] For this purpose, initially, all glassware were placed in a $1: 3$ of $\mathrm{HCl} / \mathrm{HNO}_{3}$ solution and then rinsed three times with triply distilled water. After that, by using ice and stirring, the sodium borohydride was chilled to roughly $00^{\circ} \mathrm{C}$. A $1.0 \mathrm{~mL}$ portion of $0.01 \mathrm{mM} \mathrm{AgNO}_{3}$ was added to $20 \mathrm{~mL}$ of the stirring $6.2 \mathrm{mM} \mathrm{NaBH}_{4}$ solution using a dropper (one drop per second). Stirring was stopped after complete addition of $\mathrm{AgNO}_{3}$.

(ii) Neutral AgNPs. The method proposed by Zandi-Atashbar et al. [20] was employed in which rice starch was used as reducing agent. For this purpose, the milled rice samples were used directly without any preprocessing. The samples were dried by an overnight storing at $60^{\circ} \mathrm{C}$. Subsequently, a $100.0 \mathrm{mg}$ portion of the rice powder was added to $10.0 \mathrm{~mL}$ buffer solution in a test tube and then placed in a boiling water bath for $15.0 \mathrm{~min}$. Subsequently, $1.0 \mathrm{~mL} \mathrm{AgNO}_{3}(0.01 \mathrm{M})$ was added to the tube and heated for an additional $5.0 \mathrm{~min}$ until the colour of the solution became golden. After cooling the solution to room temperature, the absorbance spectrum of the resultant solution was recorded over the reagent blank.

(iii) Positively Charged AgNPs. This type of AgNPs was synthesized according to the procedure suggested by Abbaszadegan et al. [21]. In brief, all laboratory glassware were put in a $1: 3$ of $\mathrm{HCl} / \mathrm{HNO}_{3}$ solution and then rinsed thoroughly three times with triply distilled water. Subsequently, a total of $1 \mathrm{~mL}$ of $0.01 \mathrm{M} \mathrm{AgNO}_{3}$ aqueous solution was added to $20 \mathrm{~mL}$ of $6.2 \mathrm{mM}$ 1-dodecyl-3-methylimidazolium chloride $\left(\left[\mathrm{C}_{12} \mathrm{mim}\right][\mathrm{Cl}]\right)$ aqueous solution. After vigorous stirring of the resultant solution, the freshly prepared $0.4 \mathrm{M} \mathrm{NaBH}_{4}$ aqueous solution was then added using a dropper until the colour of the solution turned golden. Afterwards, in order to remove the excess amount of ionic liquids, the colloidal solution was centrifuged for $20 \mathrm{~min}$. The prepared suspension was then stored at room temperature.

We characterized our colloidal silver suspensions, first with the help of UV-visible spectra and, second, by transmission electron microscopy (TEM; JEM 2010, Jeol, Tokyo, Japan) operated at an accelerating voltage of $100 \mathrm{kV}$. Several TEM images were prepared for each synthesized AgNPs and an average size of 250 particles was recorded. We also determined the surface charge of the synthesized AgNPs by zeta potential analysis using a zeta potential analyser (Zeta Plus, Brookhaven Instruments, NY). The concentration of the aqueous solution of the synthesized AgNPs was determined according to the procedure proposed by Zhang et al. [22].

2.2. Evaluation of Antibacterial Activity. A combination of gram-negative and gram-positive bacteria was selected. The gram-positive microorganisms used in this study were staphylococcus aureus (ATCC29737), Streptococcus mutans (ATCC35668), and Streptococcus pyogenes (ATCC8668), and the gram-negative ones were Escherichia coli (ATCC15224) and Proteus vulgaris (ATCC7829). The microorganisms were cultured in a Brain Heart Infusion (BHI) broth overnight and then stored in 20 percent glycerol at $-70^{\circ} \mathrm{C}$.

The antibacterial assessment was performed using two methods. 
(i) Well Diffusion Method. The pure cultures of microorganisms were subcultured in BHI broth at $37^{\circ} \mathrm{C}$ in a shaker incubator. Then, the bacterial suspension was prepared and spectrophotometrically adjusted to match the turbidity of $1.5 \times 10^{-8} \mathrm{CFU}$ (in $\mathrm{OD}_{600}$ ). Subsequently, $100 \mu \mathrm{L}$ of fresh culture of each test organism was spread on Mueller-Hinton agar plates. To allow the cultures to be absorbed, the plates were left standing for $7 \mathrm{~min}$. To evaluate the antibacterial activity of nanoparticles, $5 \mathrm{~mm}$ wells were punched into the Mueller-Hinton agar plates using a gel puncture. The bottoms of the wells were then sealed by 0.8 percent agar to avoid nanoparticle leakage. Subsequently, AgNPs suspensions were serially diluted five times, and then $100 \mu \mathrm{L}$ of each suspension was poured onto individual wells, using a micropipette. The plates were incubated for $24 \mathrm{~h}$ at $37^{\circ} \mathrm{C}$; and then, the zones of inhibitions were measured in diameter. In this experiment, ampicillin $(10 \mathrm{mg} / \mathrm{mL})$ was used as positive and distilled water as negative controls. All experiments were performed in triplicate.

(ii) Microdilution Method. The minimum inhibitory concentration (MIC) of the AgNPs was assessed by the microdilution method according to the guidelines presented by the Clinical and Laboratory Standards Institute [23]. The MIC was defined as the lowest concentration of antimicrobial agents that inhibited 90 percent of the bacterial growth after an overnight incubation in comparison with the negative control. For this purpose, serial dilutions from each AgNP were prepared in a 96-well microplate with $90 \mu \mathrm{L}$ Mueller-Hinton Broth $(\mathrm{MHB})$ medium. Each microbial strain was cultured in $\mathrm{MHB}$ to match the turbidity of $1.5 \times 10^{8} \mathrm{CFU} / \mathrm{mL}$. To prepare bacterial suspensions for inoculation, this suspension was diluted to yield $5 \times 10^{6} \mathrm{CFU} / \mathrm{mL}$. Finally, $10 \mu \mathrm{L}$ of the prepared suspension was inoculated into each microplate. After an overnight incubation at $37^{\circ} \mathrm{C}$, the optical density of the wells was obtained by an ELISA reader apparatus (BioTek, Power Wave XS2) at a wavelength of 600. In this assessment, ampicillin and culture media served as positive and negative controls, respectively.

\section{Results}

3.1. Synthesis and Characterization of the Silver Nanoparticles. The peak of the Plasmon resonance band of the synthesized AgNPs was observed at $400 \mathrm{~nm}$ (Figure 1). According to the TEM images, the average recorded sizes of 250 negatively, neutrally, and positively charged AgNPs were $7.5 \mathrm{~nm}, 10.1 \mathrm{~nm}$, and $9.0 \mathrm{~nm}$, respectively. The sample TEM images are provided in Figure 2.

The concentrations of the synthesized AgNPs were calculated as $9.7 \times 10^{-8}, 4 \times 10^{-8}$, and $5.7 \times 10^{-8} \mathrm{~mol} / \mathrm{L}$ for negative, neutral, and positive AgNPs. It should be noted that the most widely cited procedures for the estimation of the concentration of metallic nanoparticles are (1) using elemental analysis methods, such as inductively coupled plasma (ICP) emission spectroscopy, (2) precipitating AgNPs and dispersing the weighted amount of them in the desired solvent, and (3) using the size and absorbance of the synthesized nanoparticles. The third procedure is suggested by Zhang et al. [22]. In

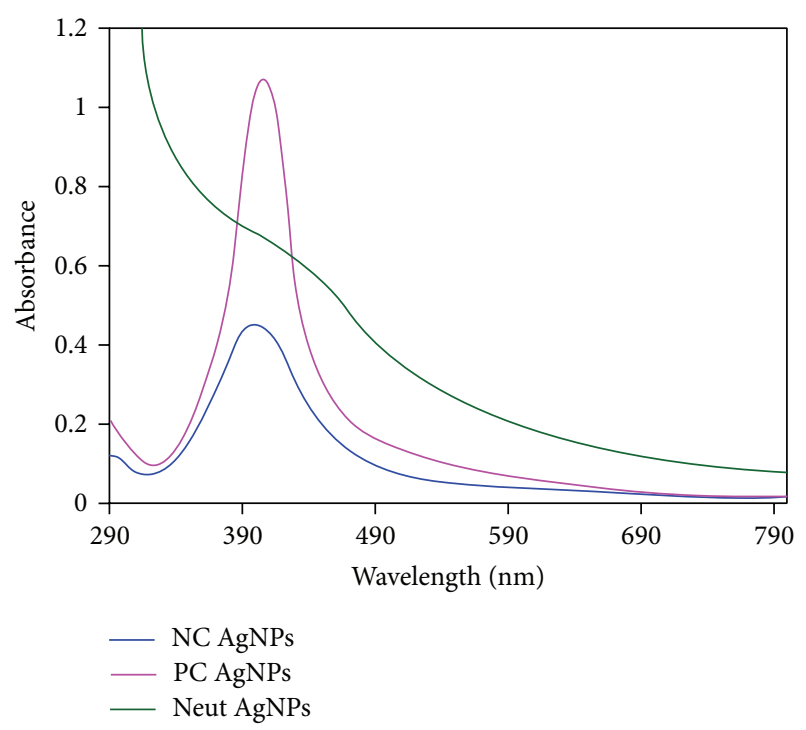

FIGURE 1: UV-Visible spectra of negative, positive, and neutral AgNPs. Negatively charged silver nanoparticles, NC AgNPS; positively charged silver nanoparticles, PC AgNPs; neutrally charged silver nanoparticles, Neut AgNPs.

this method, the concentrations are reported in molar units (mol/L).

The magnitude of the surface charge of positive, neutral, and negative AgNPs was $+50.0,0.0$, and $-38.0 \mathrm{mV}$, respectively.

3.2. Evaluation of the Antibacterial Activity. Figure 3 shows the inhibition zones induced by each AgNP solution in different concentrations against the selected bacterial species. The sample visual results are shown in Figure 4. Positively charged AgNPs presented the greatest inhibition zones against all organisms tested, in all concentrations used, when compared with the other two AgNPs. Negatively charged and neutral AgNPs did not show sufficient antibacterial activity against $P$. vulgaris in any concentration tested. Table 1 shows the MIC quantities for the selected gram-positive and gram-negative bacteria exposed to the tested AgNPs. The MIC could not be determined for neutral AgNPs against $P$. vulgaris. The MIC for negative AgNPs was only determined for S. aureus. Among the tested organisms $P$. vulgaris was confirmed as the least sensitive bacterial species.

\section{Discussion}

In our experiment, we found that the surface charge of the AgNPs can influence bactericidal activity. The positively charged AgNPs were the most effective particles and the negatively charged ones were the least effective particles against the microorganisms tested. Furthermore, the neutrally charged particles were potent against most bacterial species.

Generally, the antibacterial activity is related to the local activity of the material that eradicates the bacteria or reduces their growth, without exerting general toxicity to the tissues [29]. Several investigations have reported that the 


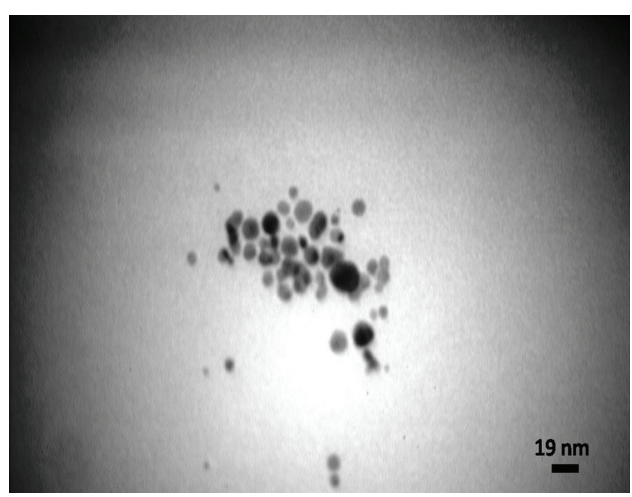

(a)

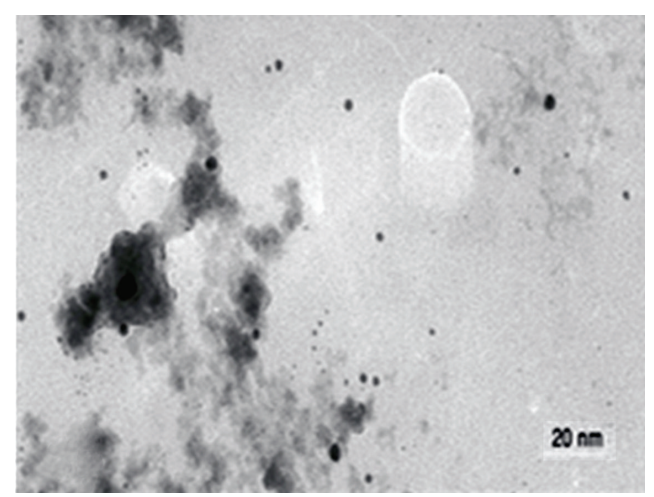

(b)

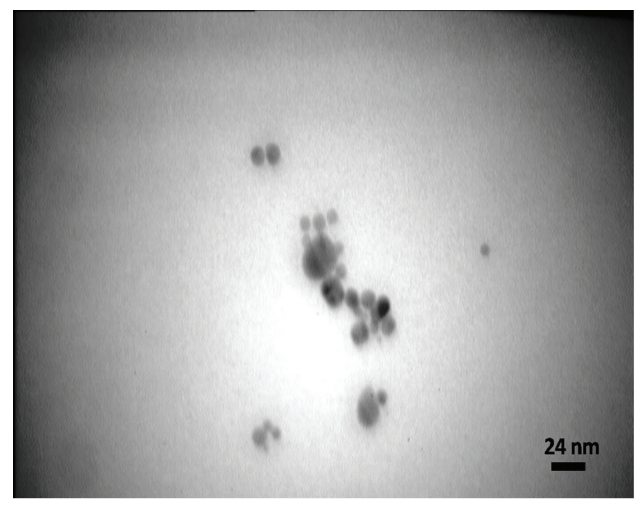

(c)

FIGURE 2: TEM images of the silver NPs synthesized in this study. (a) Negatively charged silver nanoparticles, (b) neutral silver nanoparticles, and (c) positively charged silver nanoparticles.

TABLE 1: The minimum inhibitory concentration values (mol/L) of different AgNPs against the examined bacterial species (ND: not determined).

\begin{tabular}{lccc}
\hline $\begin{array}{l}\text { Bacterial } \\
\text { species }\end{array}$ & $\begin{array}{c}\text { Positively } \\
\text { charged AgNPs }\end{array}$ & Neutral AgNPs & $\begin{array}{c}\text { Negatively } \\
\text { charged AgNPs }\end{array}$ \\
\hline $\begin{array}{l}\text { Staphylococcus } \\
\text { aureus }\end{array}$ & $5.7 \times 10^{-12}$ & $4 \times 10^{-9}$ & $9.7 \times 10^{-8}$ \\
$\begin{array}{l}\text { Escherichia coli } \\
\text { Streptococcus }\end{array}$ & $5.7 \times 10^{-12}$ & $4 \times 10^{-10}$ & $\mathrm{ND}$ \\
$\begin{array}{l}\text { mutans } \\
\begin{array}{l}\text { Streptococcus } \\
\text { pyogenes }\end{array}\end{array}$ & $5.7 \times 10^{-11}$ & $4 \times 10^{-8}$ & $\mathrm{ND}$ \\
$\begin{array}{l}\text { Proteus vulgaris } \\
\text { Prot }\end{array}$ & $5.7 \times 10^{-10}$ & $4 \times 10^{-8}$ & $\mathrm{ND}$ \\
\hline
\end{tabular}

parameters involved in the antibacterial activity of AgNPs are a combination of both physical and chemical features, such as size, shape, and surface-volume ratio of the nanoparticles, as well as their method of synthesis $[1,9]$.

In the present in vitro study, spherical AgNPs with an average size of $7.5-10.1 \mathrm{~nm}$ were synthesized by different methods, providing three different electrical surface charges to assess the effect of the surface charge and its role in antibacterial activity against certain gram-positive and gramnegative bacteria. Although the tested nanoparticles were synthesized by different methodologies, in fact the resultant nanoparticles will govern their antibacterial properties. According to the characterization results, the differently charged AgNPs were almost similar in their size and shape.

The conduction and valence bands of silver nanoparticles usually lie close to each other where the electrons are moving freely. These free electrons give rise to a surface plasmon resonance absorption band. Spherical silver nanoparticles at a size less than $20 \mathrm{~nm}$ display a single surface plasmon resonance band, usually at $400 \mathrm{~nm}$. The UV/Vis absorption spectra of the synthesized AgNPs are shown in Figure 1. As is shown, the peak of the SPR band of all synthesized AgNPs was observed at $400 \mathrm{~nm}$. However, there was an unusual spectrum for neutral AgNPs. It seems that this phenomenon is due to an occurrence of overlap between the absorbance of silver and starch. As a result, the surface plasmon resonance band of neutral AgNPs appeared to be unusual.

The results obtained by well diffusion tests were in good agreement with the microdilution tests, where positively charged AgNPs presented the greatest antibacterial activity against all organisms tested and in all concentrations used, while neutral and negative AgNPs provided the intermediate and lowest bactericidal activity. The diameters of zone of inhibition for positively charged AgNPs were larger against all bacterial species compared to neutrally and negatively charged AgNPs. The MIC results indicated that positively charged AgNPs were active in much lower concentrations against all test organisms compared to other AgNPs (100 

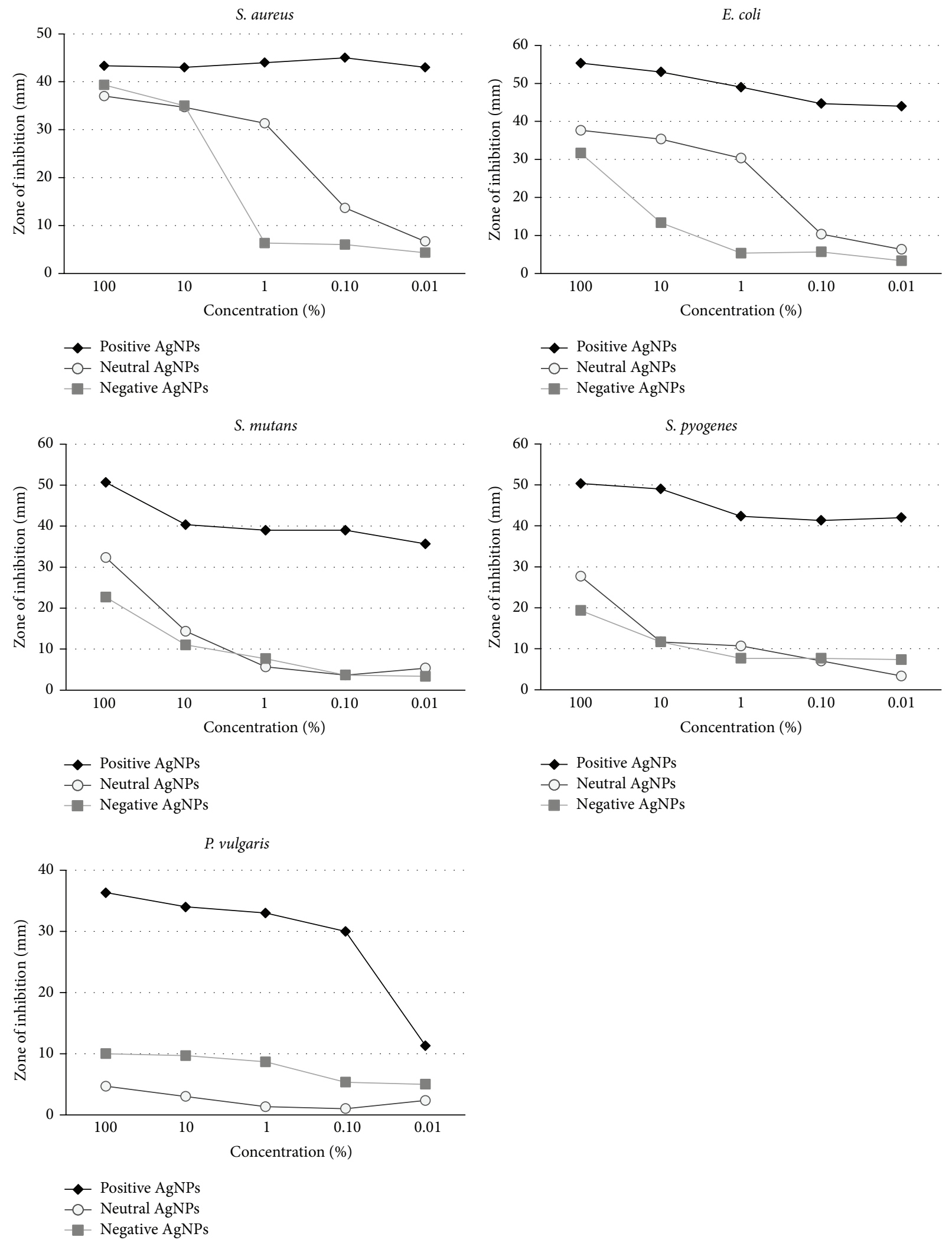

FIgURE 3: The size of the zones of inhibition in mm against target organisms when treated with different concentrations of the AgNPs. 


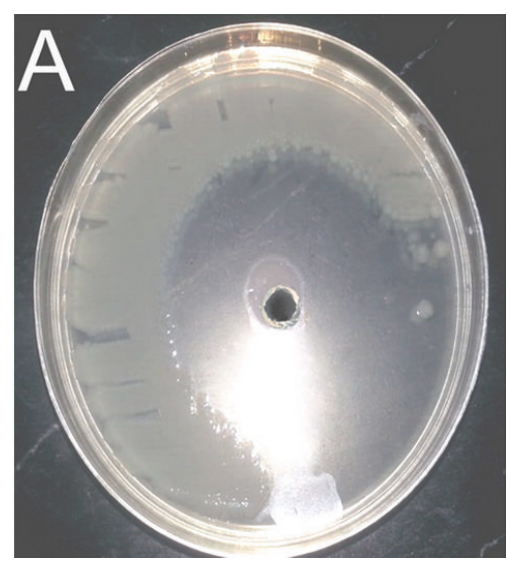

(a)

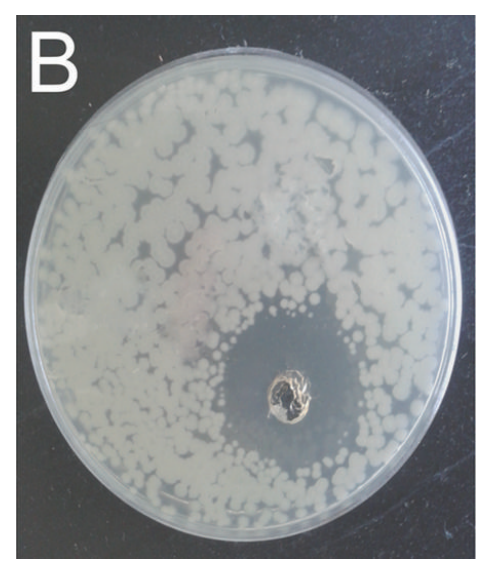

(b)

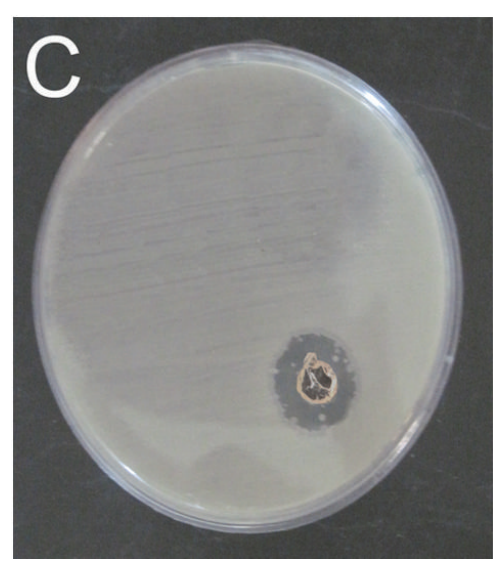

(c)

FIgURE 4: The zones of inhibition against S. mutans when treated with positive AgNPs (a), neutral AgNPs (b), and negative AgNPs (c).

to 1000 times lower). The MIC against some test organisms could not be determined for neutral and negative AgNPs, as they were unable to kill $90 \%$ of them even in their full concentration forms. This implies that the positively charged AgNPs synthesized using our approach have promising antibacterial effectiveness against a broad range of bacteria. In contrast, for neutrally and negatively charged AgNPs, smaller zones of inhibition and higher MICs indicate an inferior antibacterial potential compared to positive nanoparticles.

The results of our study were generally in line with the findings achieved by Guzman et al. [30]. In their study, different sizes of AgNPs, as well as also reducing agents, induced different antibacterial activity against $E$. coli and $S$. aureus. Therefore, the difference in antimicrobial activity of our tested AgNPs may be attributed to the different synthesis methods applied in the current investigation. It is notable that the AgNPs employed in our study were also synthesized by different capping and reducing agents for preparation of differently charged AgNPs.

This strategy of inducing charge on the surface of the nanoparticles has also been employed in recent researches to generate AgNPs with higher antimicrobial efficacy $[15,17,18]$. However, to the best of our knowledge, the application of imidazole to coat the AgNPs for the preparation of positively charged AgNPs has not been previously investigated by other researchers.

Electrostatic attraction between positively charged AgNPs and negatively charged bacterial cells is necessary for the antibacterial effectiveness of the AgNPs and this attraction is managed by the charge of the AgNPs and the microorganisms $[3,9,12,31]$. This attraction probably overcomes other factors, such as size and shape that can influence the bacterial cell death. The clear impact of charge over the other parameters influencing the antibacterial activity has also been shown in the current study in which the AgNPs of the smallest size (negatively charged: $7.5 \mathrm{~nm}$ ) presented the least antibacterial activity.

It has been proved that the cellular membrane of the bacteria has a negative charge due to the presence of carboxyl, phosphate, and amino groups [32]. Hence, the repulsion between the bacteria and negatively charged AgNPs could result in the formation of an electrostatic barrier by limiting the interaction between the AgNPs and the bacteria. Considering this point, the finding that the least antibacterial activity was observed on negatively charged AgNPs might be explained. With a reduction in the magnitude of the negatively charged AgNPs, the antibacterial activity will increase [9]. The fact that the antibacterial activity of the AgNPs is dependent on their surface charge was verified with the results of the current study, which showed the intermediate bactericidal activity for neutral AgNPs and the strongest activity for positively charged AgNPs. In addition, the attraction of positively charged AgNPs to sulfur- and phosphorus-containing proteins of bacteria could be another factor for the dissimilar antibacterial effectiveness of AgNPs with different surface charges [33, 34].

Two previous works demonstrated that the AgNPs were more active against gram-negative bacteria regardless of their resistance level $[12,13]$. In current study, $P$. vulgaris was the most resistant test bacteria, which needed a full concentration of positively charged AgNPs to obtain MIC. Furthermore, it was also resistant against neutral and negatively charged AgNPs. On the other side, although the MIC against E. coli could not be determined for negatively charged AgNPs, it was depicted as the lowest determined concentration among bacterial strains for neutrally and positively charged AgNPs. Therefore, our results suggest that the antibacterial activity of AgNPs may be associated with the characteristics of the bacterial species.

The discrepancy between the results of the current study and previous published reports presented in Table 2 can be attributed to the different bacterial strains, different AgNPs, and antimicrobial methodologies employed.

Ideally, further investigations can be performed regarding the cytocompatibility of our synthesized AgNPs on the eukaryotic cells.

Future investigations focusing on the synthesis of differently charged AgNPs with different counter ions and alkyl 
TABLE 2: Previous published reports regarding the antibacterial activity of AgNPs with different characteristics against our test organisms.

\begin{tabular}{lccc}
\hline Studies & Physical properties of AgNPs & Bacteria & MIC (m/L) \\
\hline Kim et al. 2007 [24] & $13.4 \mathrm{~nm}$ (negatively charged) & E. coli & $6.6 \times 10^{-9}$ \\
& & S. aureus & $3.3 \times 10^{-8}$ \\
Agnihotri et al. 2014 [25] & $7 \mathrm{~nm}$ (negatively charged) & E. coli & 1.8 to $8.3 \times 10^{-4}$ \\
& & S. aureus & $6.5 \times 10^{-4}$ \\
Hernández-Sierra et al. 2008 [26] & $25 \mathrm{~nm}$ (charge not determined) & S. mutans & $4.5 \times 10^{-5}$ \\
Lara et al. 2010 [27] & $100 \mathrm{~nm}$ (charge not determined) & S. pyogenes & $6.3 \times 10^{-2}$ \\
Chudasama et al. 2010 [28] & $8.2 \mathrm{~nm}$ (charge not determined) & P. vulgaris & $2.5 \times 10^{-3}$ \\
\hline
\end{tabular}

chain lengths can shed light on the bioactivity of the AgNPs and enable us to find the most efficient AgNPs with higher bactericidal activity and biocompatibility.

\section{Conclusion}

Under the experimental conditions of this study, it is concluded that the surface charge plays an important role in bactericidal activity of AgNPs against both gram-positive and gram-negative bacteria. Among different AgNPs tested, the positively charged NPs were the most effective antimicrobial materials against all tested bacterial species.

\section{Conflict of Interests}

The authors declare that there is no conflict of interests regarding the publication of this paper.

\section{Acknowledgments}

The authors thank the Vice-Chancellery of Shiraz University of Medical Sciences. Also, the authors would like to thank Dr. Shahram Hamedani and Dr. Mehrdad Vosooghi for their valuable comments to improve the quality of the paper.

\section{References}

[1] R. P. Allaker, "The use of nanoparticles to control oral biofilm formation," Journal of Dental Research, vol. 89, no. 11, pp. 11751186, 2010.

[2] S. Pal, Y. K. Tak, and J. M. Song, "Does the antibacterial activity of silver nanoparticles depend on the shape of the nanoparticle? A study of the gram-negative bacterium Escherichia coli," Applied and Environmental Microbiology, vol. 73, no. 6, pp. 17121720, 2007.

[3] I. Sondi and B. Salopek-Sondi, "Silver nanoparticles as antimicrobial agent: a case study on E. coli as a model for Gramnegative bacteria," Journal of Colloid and Interface Science, vol. 275, no. 1, pp. 177-182, 2004.

[4] K. B. Holt and A. J. Bard, "Interaction of silver(I) ions with the respiratory chain of Escherichia coli: an electrochemical and scanning electrochemical microscopy study of the antimicrobial mechanism of micromolar $\mathrm{Ag}^{+}$, Biochemistry, vol. 44, no. 39, pp. 13214-13223, 2005.

[5] J. Thiel, L. Pakstis, S. Buzby et al., "Antibacterial properties of silver-doped titania," Small, vol. 3, no. 5, pp. 799-803, 2007.

[6] G. A. Martinez-Castanon, N. Niño-Martínez, F. MartínezGutierrez, J. R. Martínez-Mendoza, and F. Ruiz, "Synthesis and antibacterial activity of silver nanoparticles with different sizes," Journal of Nanoparticle Research, vol. 10, no. 8, pp. 1343-1348, 2008.

[7] S. Inphonlek, N. Pimpha, and P. Sunintaboon, "Synthesis of poly(methyl methacrylate) core/chitosan-mixed-polyethyleneimine shell nanoparticles and their antibacterial property," Colloids and Surfaces B: Biointerfaces, vol. 77, no. 2, pp. 219-226, 2010.

[8] Z.-M. Xiu, Q.-B. Zhang, H. L. Puppala, V. L. Colvin, and P. J. J. Alvarez, "Negligible particle-specific antibacterial activity of silver nanoparticles," Nano Letters, vol. 12, no. 8, pp. 4271-4275, 2012.

[9] A. M. El Badawy, R. G. Silva, B. Morris, K. G. Scheckel, M. T. Suidan, and T. M. Tolaymat, "Surface charge-dependent toxicity of silver nanoparticles," Environmental Science and Technology, vol. 45, no. 1, pp. 283-287, 2011.

[10] M. T. Madigan, Brock Biology of Microorganisms, vol. 11th, SciELO Espana, 2005.

[11] S. Baron, Medical Microbiology, University of Texas Medical Branch, Galveston, Tex, USA, 4th edition, 1996.

[12] M. Singh, S. Singh, S. Prasad, and I. Gambhir, "Nanotechnology in medicine and antibacterial effect of silver nanoparticles," Digest Journal of Nanomaterials and Biostructures, vol. 3, no. 3, pp. 115-122, 2008.

[13] S. Shrivastava, T. Bera, A. Roy, G. Singh, P. Ramachandrarao, and D. Dash, "Characterization of enhanced antibacterial effects of novel silver nanoparticles," Nanotechnology, vol. 18, no. 22, Article ID 225103, 2007.

[14] Y. Zhou, Y. Kong, S. Kundu, J. D. Cirillo, and H. Liang, "Antibacterial activities of gold and silver nanoparticles against Escherichia coli and bacillus Calmette-Guerin," Journal of Nanobiotechnology, vol. 10, article 19, 2012.

[15] D. van Phu, L. A. Quoc, N. N. Duy et al., "Study on antibacterial activity of silver nanoparticles synthesized by gamma irradiation method using different stabilizers," Nanoscale Research Letters, vol. 9, no. 1, article 162, 2014.

[16] A. K. Suresh, D. A. Pelletier, W. Wang, J. L. Morrell-Falvey, B. $\mathrm{Gu}$, and M. J. Doktycz, "Cytotoxicity induced by engineered silver nanocrystallites is dependent on surface coatings and cell types," Langmuir, vol. 28, no. 5, pp. 2727-2735, 2012.

[17] K. J. Lee, L. M. Browning, P. D. Nallathamby, and X.-H. Xu, "Study of charge-dependent transport and toxicity of peptidefunctionalized silver nanoparticles using zebrafish embryos and single nanoparticle plasmonic spectroscopy," Chemical Research in Toxicology, vol. 26, no. 6, pp. 904-917, 2013.

[18] T. Silva, L. R. Pokhrel, B. Dubey, T. M. Tolaymat, K. J. Maier, and X. Liu, "Particle size, surface charge and concentration dependent ecotoxicity of three organo-coated silver nanoparticles: comparison between general linear model-predicted and 
observed toxicity," Science of the Total Environment, vol. 468469, pp. 968-976, 2014.

[19] L. Mulfinger, S. D. Solomon, M. Bahadory, A. V. Jeyarajasingam, S. A. Rutkowsky, and C. Boritz, "Synthesis and study of silver nanoparticles," Journal of Chemical Education, vol. 84, no. 2, pp. 322-325, 2007.

[20] N. Zandi-Atashbar, B. Hemmateenejad, and M. Akhond, "Determination of amylose in Iranian rice by multivariate calibration of the surface plasmon resonance spectra of silver nanoparticles," Analyst, vol. 136, no. 8, pp. 1760-1766, 2011.

[21] A. Abbaszadegan, M. Nabavizadeh, A. Gholami et al., "Positively charged imidazolium-based ionic liquid-protected silver nanoparticles: a promising disinfectant in root canal treatment," International Endodontic Journal, 2014.

[22] J. Zhang, Y. Fu, D. Liang, R. Y. Zhao, and J. R. Lakowicz, "Fluorescent avidin-bound silver particle: a strategy for single target molecule detection on a cell membrane," Analytical Chemistry, vol. 81, no. 3, pp. 883-889, 2009.

[23] M. A. Wikler, Performance Standards for Antimicrobial Susceptibility Testing: Twentieth Informational Supplement, Clinical and Laboratory Standards Institute, 2010.

[24] J. S. Kim, E. Kuk, K. N. Yu et al., "Antimicrobial effects of silver nanoparticles," Nanomedicine: Nanotechnology, Biology, and Medicine, vol. 3, no. 1, pp. 95-101, 2007.

[25] S. Agnihotri, S. Mukherji, and S. Mukherji, "Size-controlled silver nanoparticles synthesized over the range 5-100 nm using the same protocol and their antibacterial efficacy," RSC Advances, vol. 4, no. 8, pp. 3974-3983, 2014.

[26] J. F. Hernández-Sierra, F. Ruiz, D. C. C. Pena et al., “The antimicrobial sensitivity of Streptococcus mutans to nanoparticles of silver, zinc oxide, and gold," Nanomedicine, vol. 4, no. 3, pp. 237240, 2008.

[27] H. H. Lara, N. V. Ayala-Núñez, L. C. I. del Turrent, and C. R. Padilla, "Bactericidal effect of silver nanoparticles against multidrug-resistant bacteria," World Journal of Microbiology and Biotechnology, vol. 26, no. 4, pp. 615-621, 2010.

[28] B. Chudasama, A. K. Vala, N. Andhariya, R. V. Mehta, and R. V. Upadhyay, "Highly bacterial resistant silver nanoparticles: synthesis and antibacterial activities," Journal of Nanoparticle Research, vol. 12, no. 5, pp. 1677-1685, 2010.

[29] M. J. Hajipour, K. M. Fromm, A. Akbar Ashkarran et al., "Antibacterial properties of nanoparticles," Trends in Biotechnology, vol. 30, no. 10, pp. 499-511, 2012.

[30] M. Guzman, J. Dille, and S. Godet, "Synthesis and antibacterial activity of silver nanoparticles against gram-positive and gramnegative bacteria," Nanomedicine: Nanotechnology, Biology, and Medicine, vol. 8, no. 1, pp. 37-45, 2012.

[31] J. Fabrega, J. C. Renshaw, and J. R. Lead, "Interactions of silver nanoparticles with Pseudomonas putida biofilms," Environmental Science and Technology, vol. 43, no. 23, pp. 9004-9009, 2009.

[32] A. van der Wal, W. Norde, A. J. B. Zehnder, and J. Lyklema, "Determination of the total charge in the cell walls of Grampositive bacteria," Colloids and Surfaces B: Biointerfaces, vol. 9, no. 1-2, pp. 81-100, 1997.

[33] A.-T. Le, P. T. Huy, L. T. Tam, P. D. Tam, N. V. Hieu, and T. Q. Huy, "Novel silver nanoparticles: synthesis, properties and applications," International Journal of Nanotechnology, vol. 8, no. 3-5, pp. 278-290, 2011.

[34] A.-T. Le, T. T. Le, H. H. Tran, D. A. Dang, Q. H. Tran, and D. L. $\mathrm{Vu}$, "Powerful colloidal silver nanoparticles for the prevention of gastrointestinal bacterial infections," Advances in Natural
Sciences: Nanoscience and Nanotechnology, vol. 3, no. 4, Article ID 045007, 2012. 

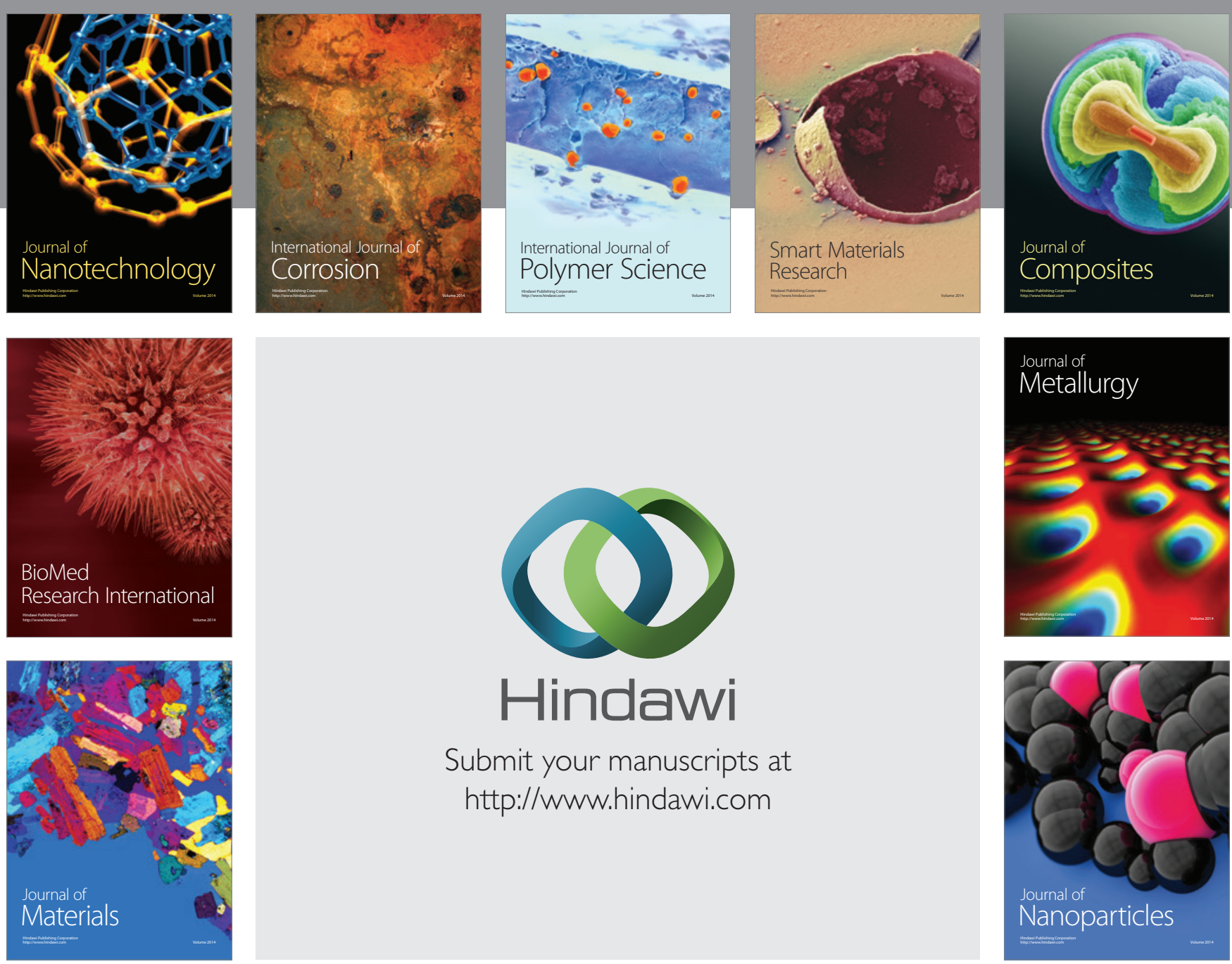

Submit your manuscripts at http://www.hindawi.com
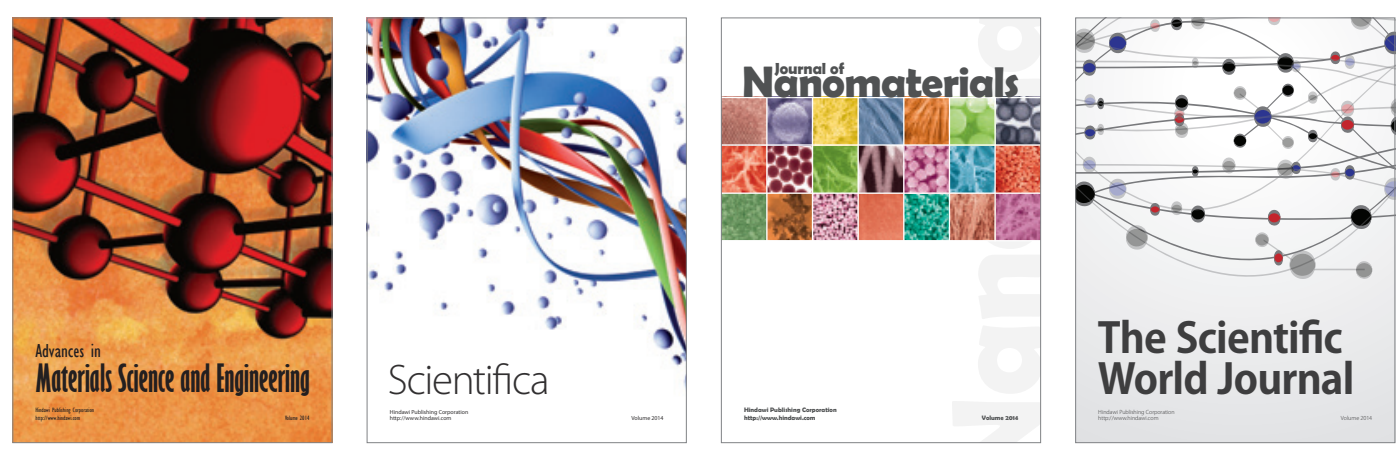

\section{The Scientific World Journal}
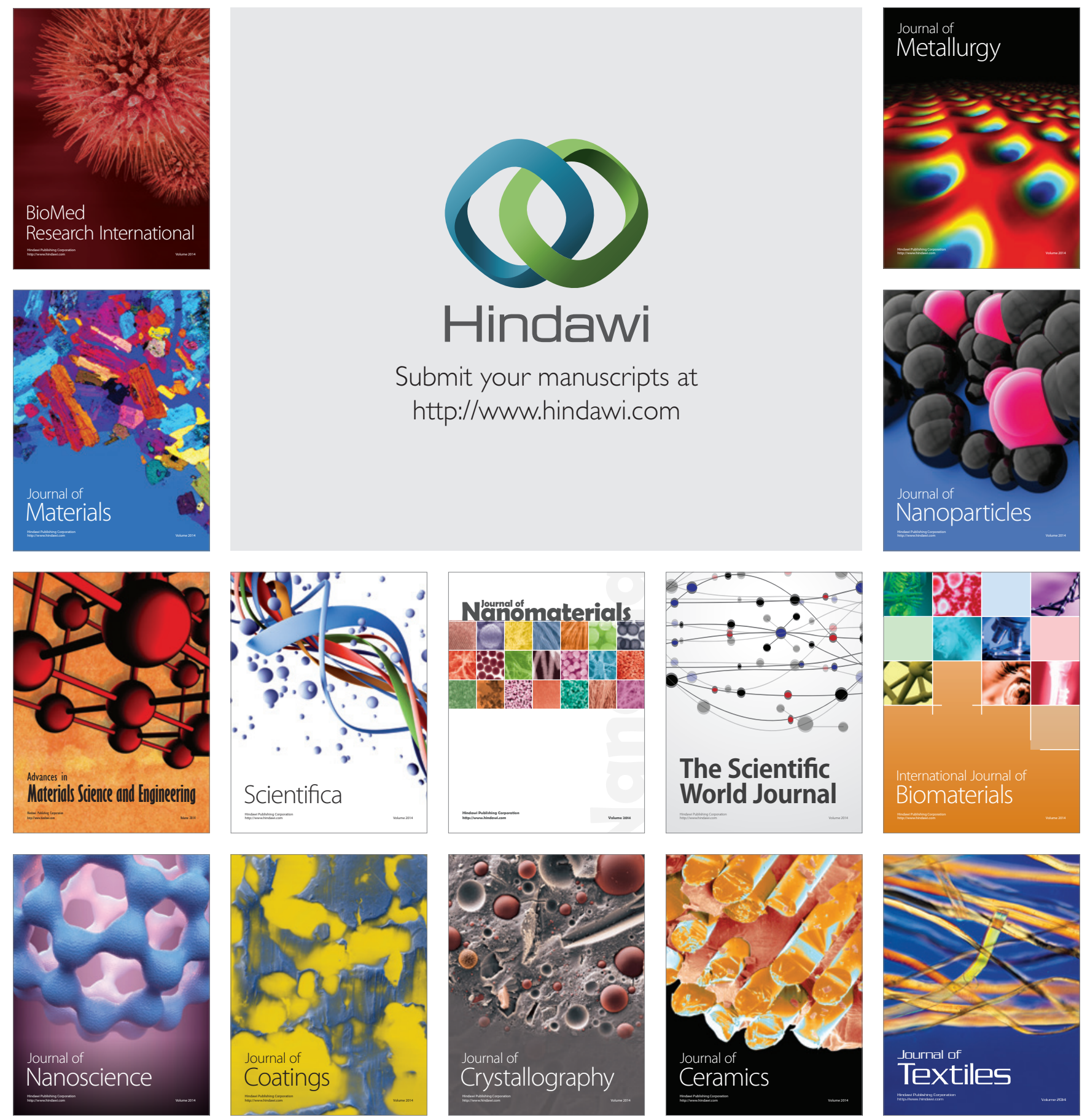